\title{
OS SABERES TRADICIONAIS DOS PESCADORES DE CARANGUEJO-UÇÁ E O MANGUEZAL: \\ O CASO DE TAMATATEUA, BRAGANÇA - PARÁ, COSTA AMAZÔNICA BRASILEIRA
}

\author{
Francisco Pereira de Oliveira ${ }^{1}$ \\ Gamaliel Tarsos de Sousa ${ }^{2}$ \\ Klayton Luiz Campelo Silva ${ }^{3}$ \\ Marcus Emanuel Barroncas Fernandes ${ }^{4}$
}

\begin{abstract}
RESUMO
O presente estudo enfoca o saber empírico e as percepções ambientais dos pescadores de caranguejouçá (Ucides cordatus) da região de Tamatateua, município de Bragança, nordeste do Pará. Visa descrever os saberes tradicionais dos pescadores deste recurso com enfoque no conhecimento ecológico a partir de suas percepções e estreita relação com o ecossistema manguezal. Fez-se uso da abordagem qualitativa de pesquisa, em que a técnica e o instrumento de pesquisa transitaram com o uso de entrevistas a partir de um questionário elaborado com perguntas semiestruturadas, respectivamente. A coleta de dados ocorreu entre os anos de 2017 e 2018, com 14 (quatorze) pescadores de caranguejo-uçá, com idade que variaram entre 22 e 62 anos, em que o processo analítico fez uso da análise de conteúdo. Os resultados demonstram que os pescadores possuem saberes ecológicos elaborados sobre o espécime caranguejo-uçá, assim como dos fenômenos naturais e ambientais. Percebem a conexão entre o ser humano e o manguezal como sinônimo de alimentação, comercialização, cultura, religiosidade, dentre outros, o que, de alguma forma, influencia diretamente nos saberes repassados de geração a geração por meio da educação não formal e informal. Constatouse, ainda, que o manejo do recurso caranguejo-uçá se deve ao processo de aprendizagem ocorrido
\end{abstract}

\footnotetext{
${ }^{1}$ Doutor em Biologia Ambiental, com ênfase em Biologia de Organismos da Zona Costeira Amazônica, pelo Programa de Pós-Graduação em Biologia Ambiental (PPBA). Possui Mestrado em Biologia Ambiental - Ênfase em Ecologia de Ecossistemas Costeiros e Estuarinos pela Universidade Federal do Pará; Especialização em Gestão de Sistema Educacional pelo Centro Universitário do Estado do Pará; graduação em Pedagogia pela Universidade Federal do Pará. Atualmente é Professor Efetivo da Universidade Federal do Pará na cadeira de Planejamento e Gestão Educacional; Pesquisador do Laboratório de Ecologia de Manguezal (UFPA); Professor do Programa de Mestrado em Linguagens e Saberes da Amazônia/UFPA. E-mail: foliveiranono@ yahoo.com.br ${ }^{2}$ Mestrando em Linguagens e Saberes da Amazônia, linha de pesquisa Educação, Cultura e Sociedade pela Universidade Federal do Pará, Especialista em Saberes Culturais e Educação da Amazônia (UFPA), possui graduação em Licenciatura Plena em Pedagogia pela Universidade Federal do Pará -UFPA (2000). Atualmente é concursado pela SEDUC/PA como especialista em educação, atuando na EEEFM Prof a Argentina Pereira, professor colaborador do Instituto de Ensino Superior do Pará (IESPA) e Secretário Escolar da Escola Municipal Pe. Paulo Corolli - Secretaria Municipal de Educação (SEMED). Tem experiência na área de Educação, com ênfase em Filosofia da Educação, atuando principalmente nos seguintes temas: educação, sustentabilidade, reserva extrativista, coletores, comunidade, professor e jovens e adultos. Professor colaborador da Faculdade de Bragança (FABRA). Professor Colaborados da Faculdade Latino Americana de Educação (FLATED). E-mail: gamaliel.tarsos@gmail.com

${ }^{3}$ Possui graduação em HISTÓRIA pela Universidade Federal do Pará (2002). Professor do Governo do Estado do Pará. Tem experiência na área de História, com ênfase em História Social da Amazônia. Atualmente é discente do Programa de Pós Graduação em Linguagens e Saberes da Amazônia (UFPA). , Atuando principalmente nos seguintes temas: Cultura, História, Modernidade, Urbanização e Cidadania no Brasil República. E-mail: klaytoncampelosilva@gmail.com

${ }^{4}$ Possui graduação em Licenciatura em Ciências Biológicas pela Universidade Federal do Amazonas (1985), mestrado em Psicologia Experimental (Comportamento Animal) pela Universidade de São Paulo (1989) e doutorado em Biologia pela Universidade de York (1997) - Inglaterra. Atualmente é Professor Associado da Universidade Federal do Pará - Campus de Bragança. Tem experiência na área de Oceanografia Biológica, com ênfase em ecologia do ecossistema manguezal, desenvolvendo pesquisas sobre produtividade primária e secundária, interação fauna e flora e questões socioambientais. E-mail: mebf@ufpa.br
} 
cotidianamente entre o parentesco (pai, filho, neto, tios e outros), assim como no processo e socialização (partilha) entre amigos do "manguezal". Doutro lado, identificou-se que mesmo utilizando-se de práticas e artes predatórias, como o gancho, os pescadores as reconhecem como tal, porém revelam a ideia de manutenção do recurso quando argumentam o respeito nos períodos de reprodução do espécime.

Palavras-chave: Manguezal. Caranguejo-uçá. Saberes da Pesca. Percepção.

\begin{abstract}
This study focuses on the empirical knowledge and environmental perceptions of Uçá crab (Ucides cordatus) fishermen from the Tamatateua region, municipality of Bragança, northeast of Pará. The main objective is to describe the fishermen's traditional knowledge on this resource focusing on the ecological knowledge from their perceptions and close relationship with the mangrove ecosystem. used the qualitative research approach, in which the technique and the research instrument were carried out using interviews from a questionnaire designed with semi-structured questions, respectively. Data collection took place between 2017 and 2018, with 14 (fourteen) fishermen of Uçá crab, aged between 22 and 62 years, in which the analytical process made use of content analysis. The results demonstrate that the fishermen have elaborated ecological knowledge about the Uçá crab specimen, as well as the natural and environmental phenomena. They perceive the connection between the human being and the mangrove as a synonym of food, marketing, culture, religiosity, among others, which, in some way, directly influence the knowledge passed on from generation to generation through non-formal and informal education. It was also found that the management of the Uçá crab resource is due to the learning process that occurs daily between kinship (father, son, grandson, uncles and others), as well as in the process and socialization (sharing) between friends of the "mangrove". On the other hand, it was identified that even using predatory practices and arts, such as the hook, the fishermen recognize them as such, but reveal the idea of maintaining the resource when arguing about the respect in the reproduction periods of the specimen.
\end{abstract}

Keywords: Mangrove. Uçá crab. Fishing knowledge. Perception.

\title{
INTRODUÇÃO
}

A educação é um meio de construção e reconstrução de conhecimentos nos campos científicos, populares, empíricos, dentre outros, e que, certamente, não ocorre apenas no ambiente escolar institucionalizado, ou seja, acontece no ambiente familiar, na igreja, na rua, nas relações sociais, sempre quando uma cultura tenta ser transmitida, de uma forma ou de outra, temos algum contato com ela.

Os conhecimentos exteriores ao ambiente escolar devem ser levados em consideração, por exemplo, as experiências da vida comum, o cotidiano do saber-fazer, as relações intra e extrafamiliares, ou seja, a educação informal. Ao se deparar com o saber tradicional dos pescadores de caranguejo-uçá numa área costeira da Amazônia, certamente, se lida com essa dimensão da educação (a informal). Todavia, há agentes sociais que usam a dualidade formal e informal, mas se compartilha do enunciado de Gohn (2010), quando enfatiza que há três dimensões da educação: formal, não formal e informal, e, que devem ser complementares e 
integrativas, e uma não se sobrepõe a outra, pois a educação formal é a escolarizada, regida por regras, sistematizada e a não formal o aprendizado é espontâneo, é social e com intencionalidade, a exemplo dos movimentos sociais. A informal é partilhada e estruturada a partir de aprendizagens naturais, enraizada pelas experiências cotidianas da vida comum, de vivências, de sua origem, religiosidade e, por certo, a ocorrência se dá pela via geracional, ou seja, "é o passado orientando o presente" (GOHN, 2010, p. 28).

As populações tradicionais que vivem em comunidades têm práticas produtivas de subsistência, onde seus saberes são aqueles repassados de geração em geração, um saber empírico e age sobre o meio ambiente com demonstração de contribuição que vai além da visão humano-natureza. Complementarmente, Diegues (1999, p. 15) destaca que "torna-se necessário resgatar os sistemas tradicionais de manejo ainda hoje praticados por essas populações, pois essas técnicas têm contribuído significativamente para a manutenção da diversidade biológica".

Ainda, há que se reconhecer o movimento simbiótico que ocorre da relação entre os ciclos sazonais, os recursos ambientais e as práticas produtivas estabelecidas pelos povos imbuídos de um sentimento de pertença, onde suas vidas são condicionadas e construídas tomando como base os ambientes em que estão inseridos, criando, certamente, culturas. De forma polida e objetiva, Diegues e Arruda (2001, p. 25), enfatizam que "um aspecto relevante na definição de culturas tradicionais é a existência de sistemas de manejo dos recursos naturais marcados pelo respeito aos ciclos naturais, e por sua exploração dentro da capacidade de recuperação das espécies de animais e plantas utilizadas”.

Nesse sentido, na Amazônia brasileira, os saberes dos povos tidos como tradicionais são constituídos nas três dimensões da educação: formal (escolarização), não formal e informal. No entanto, os povos tradicionais perpetuam suas práticas produtivas, organização social, economia, cultura e religiosidade por meio dos saberes constituído na educação não formal e informal.

É nesse contexto, que surgem os povos que residem e praticam suas atividades produtivas nas áreas estuarino-costeiras (OLIVEIRA, 2015). Em particular, aqueles que têm sua principal atividade produtiva na pesca do caranguejo-uçá (Ucides cordatus), ou seja, mantém relação estreita com o ecossistema manguezal. Este, por sua vez, tem se destacado por sua rica biodiversidade, pois é um berço de diversas espécies de fauna e flora, com grande importância ecológica e econômica. Dentre as espécies, destaca-se o caranguejo-uçá (Ucides cordatus, Linnaeus, 1763), que tem sido importante não só na cadeia de comercialização, mas 
também nas teias de relações sociais de sobrevivência e manejo dos costeiros e ribeirinhos da costa nordeste do estado do Pará (MANESCHY, 2005, MONTEIRO et al., 2014; OLIVEIRA, 2015).

Daí se faz importante perceber quais os saberes ecológicos locais empreendidos por meio da educação informal e de que forma esses são repassados de geração a geração entre os pescadores do caranguejo-uçá na Comunidade de Tamatateua, Bragança, Pará? E ainda, estes saberes ecológicos locais promovem a preservação do ecossistema manguezal e, por conseguinte, do caranguejo-uçá?

Diante desse cenário, os objetivos foram: i) estudar os saberes ecológicos locais com relação às práticas produtivas na pesca do caranguejo-uçá na Comunidade de Tamatateua, Bragança (PA) com enfoque na educação informal; ii) descrever o perfil dos pescadores (sexo, escolaridade, tempo de trabalho, jornada semanal, etc.); iii) identificar essas práticas no repasse de saberes às gerações novas, assim como as artes de pesca utilizadas no manejo do caranguejo-uçá. Certamente, tais questões suscitam análises interdisciplinares, no intuito de discutir os saberes ecológicos locais no viés da educação informal, assim como realizar uma abordagem holística das práticas produtivas empreendidas na pesca do caranguejo-uçá, na Comunidade de Tamatateua, Bragança (PA), costa amazônica brasileira.

\section{PROCEDIMENTOS METODOLÓGICOS}

\section{1 ÁREA DE ESTUDO}

O estudo envolveu os usuários ${ }^{5}$ do manguezal, especificamente os pescadores do caranguejo-uçá da comunidade de Tamatateua, Bragança (Fig.1), nordeste do estado do Pará, área da península costeira bragantina.

O local da pesquisa foi definido a partir da potencialidade conhecida na produção do caranguejo-uçá (OLIVEIRA, 2015). Tamatateua se localiza ao norte do município de Bragança, distante da sede, aproximadamente, $18 \mathrm{~km}$. A referida comunidade é constituída por pessoas que desempenham diversas atividades, entre elas destacam-se: a pesca artesanal: peixes, caranguejos e mariscos; agricultura de mandioca, feijão, tabaco e outros; servidores públicos: vigias, serventes, professores, gestores, coordenadores, agente comunitário de saúde, dentre outros.

\footnotetext{
${ }^{5}$ Pessoas que são cadastradas pela Associação dos Usuários da Reserva Extrativista Marinha Caeté-Taperaçu (ASSUREMACATA) para a apropriação e uso dos recursos naturais dos manguezais nos limites da reserva.
} 
Figura 1: Mapa de localização da comunidade de Tamatateua, Município de Bragança, costa

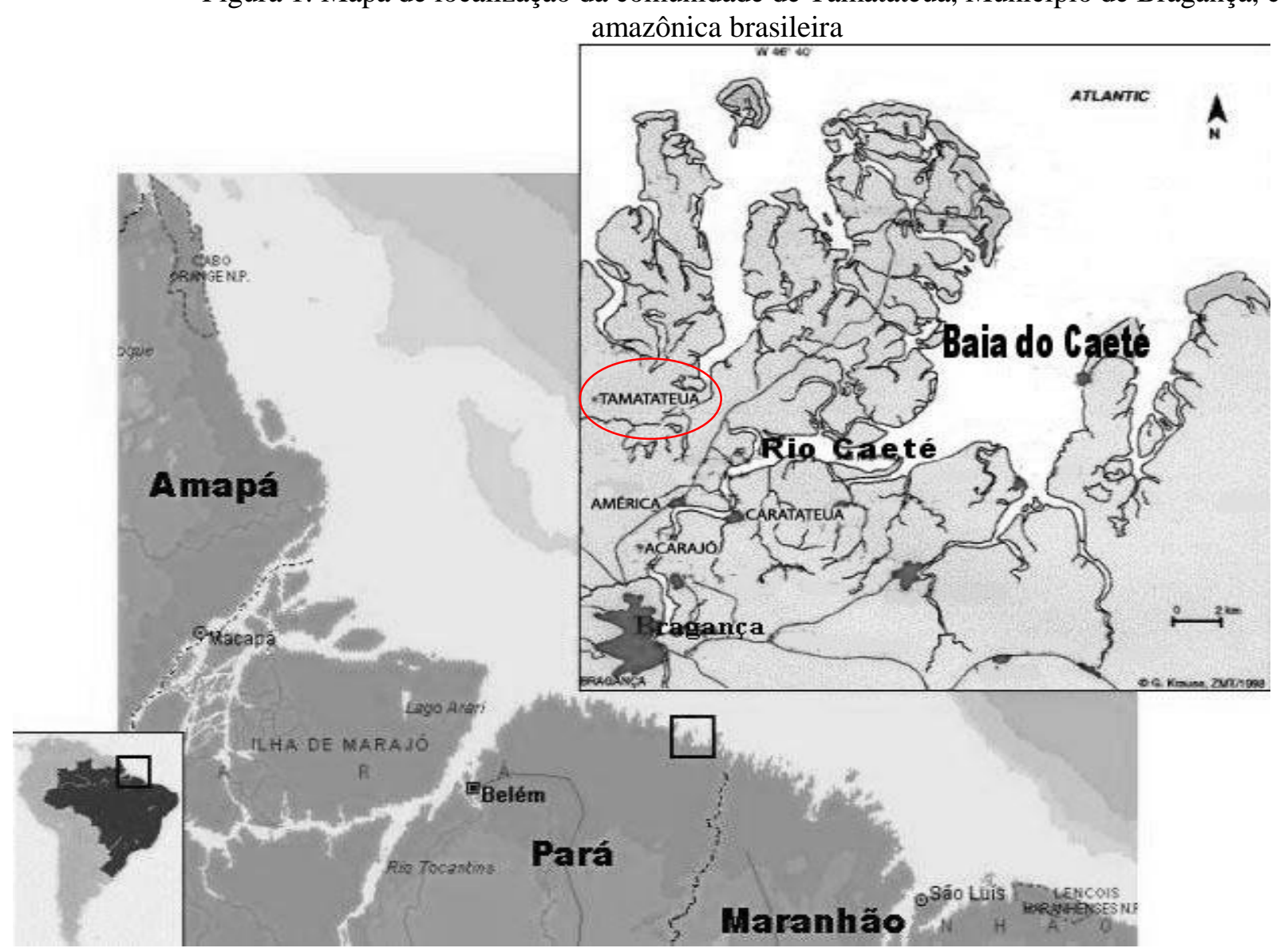

Fonte: Oliveira, 2015

\subsection{COLETA DE DADOS}

O presente estudo ocorreu nos anos de 2017 e 2018, com uma amostragem constituída de 14 (quatorze) pescadores de caranguejo-uçá, com idade entre 22 e 62 anos, estes, considerados produtores ativos no mercado de trabalho.

Foi elaborado um questionário com perguntas semiestruturadas e destinadas aos pescadores de caranguejo-uçá, com o objetivo de identificar os saberes ecológicos locais repassados de geração a geração por meio da educação informal. Logo, primou-se pela abordagem qualitativa (MINAYO, 2010) e pela abordagem quantitativa de pesquisa (RICHARDSON, 1989).

Os procedimentos de coleta seguiram os seguintes passos: 1) contato com a comunidade por meio de pessoas chave, como o coordenador e a gestora da Escola Municipal de Educação Infantil e Fundamental Braziliano Felício da Silva; 2) contato com os pescadores de caranguejo-uçá para verificar a possibilidade de conversar sobre sua prática produtiva, 
dada aceitação, marcava-se o dia e a hora; 3) entrevista com o uso do questionário; 4) estreitar as conversas, algumas perguntas eram formuladas ou reformuladas até esgotar o assunto. Adicionalmente, foi realizada a observação de campo, onde algumas vezes acompanhava o pescador na sua área de trabalho e observava como as gerações mais novas se comportavam frente ao que viam e observavam.

\subsection{ANÁLISE DE DADOS}

A coleta por questionário recebeu o tratamento da análise do conteúdo a partir dos estudos de Bauer \& Graskell (2002), com a transcrição parcial ou total da fala. Ademais, recebeu, em algumas passagens, a análise do discurso, pois se compreende que (...) não mais tratar os discursos como conjunto de signos (elementos significantes que remetem a conteúdos ou representações), mas como práticas que forma sistematicamente os objetos de que falam (FOUCAULT, 1986, p. 56).

Os dados quantitativos foram tratados mediante tabulação dos resultados numa planilha do Programa Microsoft Excel versão 2010, e depois analisados à luz da estatística descritiva (FREITAS \& MOSCAROLA, 2000).

\section{RESULTADOS E DISCUSSÃO}

\subsection{O PERFIL DOS PESCADORES DE CARANGUEJO-UÇÁ DE TAMATATEUA}

Em Tamatateua, o caranguejo-uçá ainda é um recurso pouco explorado pelos mais jovens 16-21 anos, que tendem a serem os próximos disseminadores dessa atividade, sendo o trabalho realizado ainda pelos mais velhos. A estrutura etária mostrou que a idade dos entrevistados variou de 22-62 anos, com média de 39 anos, todos do sexo masculino. Portanto, a atividade produtiva é realizada por pessoas que se encontram no auge da faixa etária dos economicamente ativos 30-39 anos.

Segundo Borcem et al (2011), esse número de maior expressão de pescadores em idade adulta, justifica-se pelo direcionamento dos mais jovens para o comércio local ou mesmo outras profissões, como pedreiros, marceneiros e outras, na maioria das vezes consideradas de maior validade do que a atividade pesqueira. Adicionalmente, percebe-se que as famílias têm incentivado os mais jovens a ingressarem na instituição escolar, o que, por vezes, levam esses jovens a buscarem outras realidades e os afasta do ambiente pesqueiro. 
Verificou-se também que a média de tempo que o pescador desenvolve o trabalho de extração do caranguejo-uçá é de 25 anos. Identificou-se ainda que frequentaram a instituição escolar (100\%), embora $86 \%$ tenham cursado ou cursam o ensino fundamental completo ou incompleto, e somente $14 \%$ cursaram ou cursam o ensino médio.

Os motivos que levaram os pescadores à evasão escolar se devem ao trabalho para ajudarem no sustento familiar, dificuldade de acesso à escola e, principalmente, pelo aspecto financeiro, pois tinham que trabalhar para obter renda, o que impedia a continuidade dos estudos, uma vez que o tempo Escola não condizia com o tempo disponível dos pescadores, pois o tempo deles, certamente, estava condicionado à sazonalidade costeira amazônica, ciclos naturais.

Os dados obtidos quanto à escolaridade dos entrevistados nos remetem a uma análise social, cujas evidências apontam para o fato de que muitas vezes o acesso à educação formal, direito do cidadão, não chega a todos ou não se adequa à vida dele, especialmente a população menos favorecida socialmente. Alves e Nishida (2003) apontam que o abandono dos estudos e a inserção precoce no mercado de trabalho resultam do contexto social e econômico em que essas comunidades estão inseridas, no qual o sucesso escolar constitui uma exceção.

Quanto à composição da renda familiar advinda de outras áreas, analisou-se que existem outras pessoas (familiar) que contribuem com a renda mensal, estas complementam por meio do trabalho doméstico (14\%), benefícios do Governo Federal, como bolsa família, bolsa verde, aposentadoria por idade e por atividade rural (1\%), mas principalmente pela agricultura (57\%), porém, 28\% não quiseram declarar (Fig. 2). 
Figura 2: Atividades complementares à renda dos pescadores de caranguejo-uçá de Tamatateua, Município de Bragança, costa amazônica brasileira

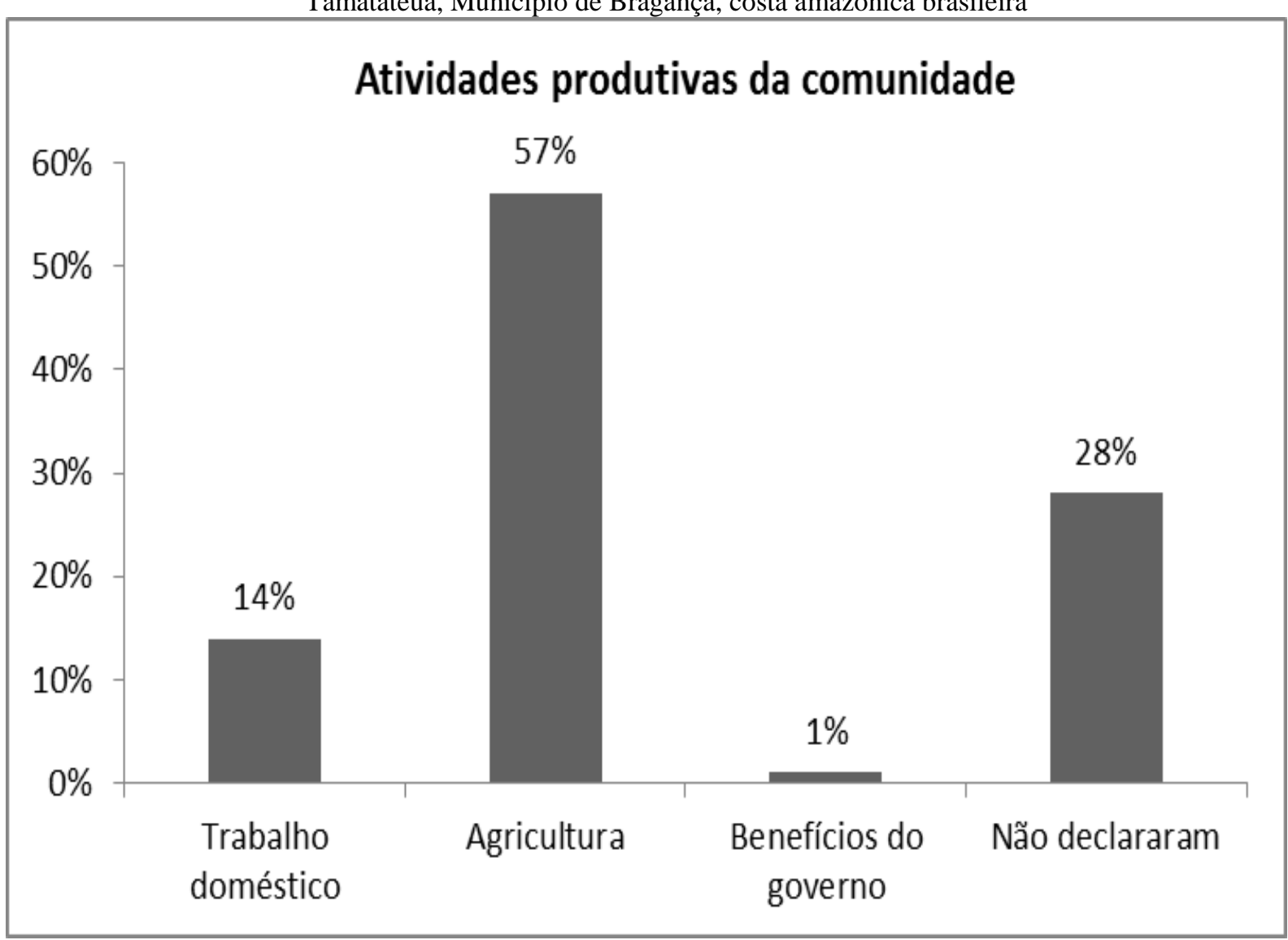

Fonte: Elaborada pelos autores

Detectou-se, ainda, que $79 \%$ aprenderam a exercer a atividade com os pais, $14 \%$ com os tios e $7 \%$ com os cunhados. Com relação ao processo de aprendizagem sobre a profissionalização na pesca do caranguejo-uçá, analisa-se que a construção do conhecimento ocorre mediante ao repasse entre gerações. Assim, o processo educativo é encaminhado, e por meio dos "educadores”, que são os próprios pais, as famílias, ou seja, uma educação herdada, como argumenta Gohn (2010, p. 20): "é o passado orientando o presente".

Os dados acima demonstraram que as atividades do pescador de caranguejo-uçá estão pareadas a outras para complementação da renda mensal, pois se entende a partir de então que somente essa prática produtiva não assegura os meios de vida das famílias desses pescadores, ou seja, torna-se uma atividade dependente de outras para o sustento cotidiano familiar. Ademais, a média de renda mensal em função da atividade produtiva de extração do caranguejo-uçá é menor que o valor do salário mínimo em 2018 (R\$998,00), o que, certamente, também custeia, diariamente, o "rancho" (a alimentação) e os apetrechos necessários para a ida ao manguezal, por exemplo, o conserto/confecção de apetrechos de pesca, aquisição de combustível para abastecer barcos de pequeno porte e canoas motorizadas, aquisição do tabaco que serve, quando feito o "porronca" (cigarro), para 
espantar os insetos durante a estadia no manguezal e a captura. Obviamente, existem outros elementos que não são cotidianos, mas fazem parte dos custos para se extrair esse recurso e, contabilmente, não se podem precisar esses valores em função de que os pescadores não costumam planificá-los ou anotá-los.

Juntado a esse condicionante, tem-se as despesas domésticas e pagamentos de pequenas dívidas em tabernas (comércios pequenos), o que dificulta ao pescador emitir uma ideia de ganhos com a atividade de pesca. Esses dados socioeconômicos, demostram, em sua maioria, que os pescadores de caranguejo-uçá estão no cômputo dos $10 \%$ mais pobres da população brasileira. Há estudos, por exemplo, de Alves e Nishida (2003) e Barbosa et al (2008) que demonstram também essa renda inferior a um salário mínimo e, por conseguinte, levaram Nordi (1992) a classificar os pescadores de caranguejo-uçá como os de menor poder aquisitivo entre os pescadores de um modo geral.

\subsection{A PRODUTIVIDADE DO CARANGUEJO-UÇÁ EM TAMATATEUA, BRAGANÇA-PA}

Dado bem interessante é que a quantidade aproximada de caranguejo-uçá (Fig. 3) extraída por semana dos manguezais pelos pescadores de Tamatateua é, em média, 23 cambadas ${ }^{6}$. Esses pescadores vão ao manguezal para a pesca por semana, em média, 3 vezes, sempre acompanhado de mais 8 pessoas, geralmente colegas de profissão ou familiares.

A renda obtida por semana é, em média, $\mathrm{R} \$ 176,00$ reais por pescador. Observa-se que o ganho mensal está inferior ao salário mínimo vigente no Brasil (2018), que é de R\$998,00. Notou-se, ainda, que esses pescadores não dispõem de seguro defeso quando há proibição de extração desse recurso no período da "andada" no período defeso ${ }^{7}$, por determinação da Lei estabelecida pela Portaria No 034 /03-N, de 24 de Junho de 2003.

Figura 3: Pescador de caranguejo no manguezal (3A), caranguejo-uçá capturado (3B), cambadas de caranguejos (3C), atividades realizadas em Tamatateua, Município de Bragança, costa amazônica brasileira

Cambada: porção média de 14 caranguejos amarrados por um fio de nylon (OLIVEIRA, 2015).

${ }^{7}$ O seguro defeso é uma política pública passiva, instituída pelo Governo Federal, que concede renda mínima ao pescador profissional artesanal durante o período de proibição da pesca em função da reprodução do espécime. Portaria IBAMA $\mathrm{N}^{\circ}$ 034/03-N, de 24/06/2003, que trata do defeso pesqueiro do recurso caranguejo-uçá para as regiões norte e nordeste do Brasil. 

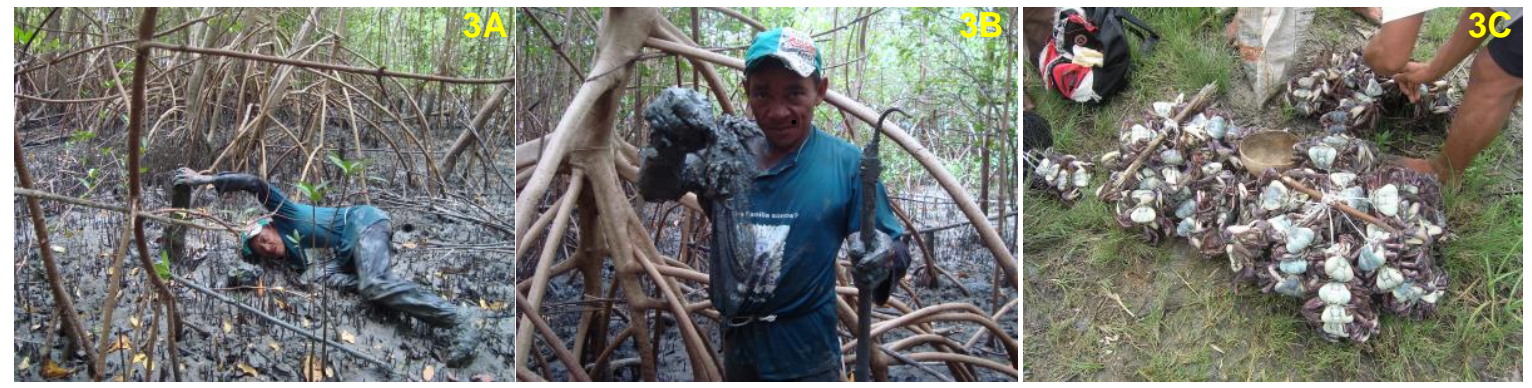

Fonte: Oliveira, 2015

De acordo com dados do IBGE/PNAD (1999), a média nacional para renda mensal está situada em 2,1 salários mínimos para os empregados não registrados, o que diverge consideravelmente da renda conseguida pelos pescadores entrevistados. Como consequência da situação descrita, muitos deles procuram um aditivo advindo de outras atividades como a pesca artesanal (peixe), o trabalho rural (agricultura) e a extração e catação de outros mariscos.

Discute-se, portanto, que os padrões insustentáveis de consumo e a produção existente, principalmente nos países industrializados como o Brasil, ocasionam o agravamento da pobreza e da desigualdade, gerando maior pressão sobre os recursos naturais e o aumento dos impactos sobre o meio ambiente (BAILÃO, 2001). Em particular, tem-se a compreensão que o auxílio defeso inexistente e a proibição da pesca no período de defeso, podem levá-los a burlar a lei e extrair o caranguejo-uçá no período de reprodução, causando, certamente, um impacto negativo e, por consequência, a esgotabilidade desse recurso, o que compromete, sobremaneira, o estoque pesqueiro.

A produtividade na captura do caranguejo-uçá desenvolvida nos manguezais pelos pescadores de Tamatateua é predominantemente masculina, ou seja, é praticamente inexistente a mão de obra da mulher no trabalho com esse crustáceo (campo/captura). Embora se constate a presença da mulher noutras atividades ligadas à pesca, como a catação (o mínimo, devido não ser o foco nessa comunidade) ou mesmo na companhia dos seus parceiros na condução da canoa a remo, isto é, quando se considera apenas como trabalho aquele valorizado economicamente, invisibiliza-se a presença da mulher na pesca considerada apenas como ajuda, por exemplo. Essa constatação é similar a de Vergara-Filho e PereiraFilho (1995) para a maioria dos estados brasileiros, havendo exceções apenas em algumas localidades, como São João da Barra (RJ), onde o número de mulheres catadoras de caranguejo é o triplo dos homens.

Outro fator que se mostrou importante como critério para extração de caranguejo-uçá é o tamanho. Os pescadores só capturam a partir de $6 \mathrm{~cm}$ de largura da carapaça, ou seja, o 
tamanho legalizado pelo Instituto Brasileiro do Meio Ambiente e dos Recursos Renováveis (IBAMA), assim como a não captura dos espécimes fêmeas. Todavia, esse critério não se deve somente às normas legais, mas sim pela aceitação do caranguejo no mercado, como afirma o Pescador A, "quanto maior mais querem comprar né”.

Ainda que não seja intencional esta prática voltada para a conservação, constitui-se uma atitude conservacionista, pois com a captura de caranguejos adultos, certamente, o estoque consegue a reposição.

\subsection{A BIOECOLOGIA DO CARANGUEJO-UÇÁ PERCEBIDO PELOS PESCADORES DE TAMATATEUA}

Quando questionados sobre o ciclo do caranguejo-uçá, foi observado que os pescadores têm um extenso conhecimento sobre o ciclo reprodutivo. Onde emitiram falas como: "tudo se inicia com a 'andada"”; outros: "é o período de reprodução"; e ainda: "período em que grandes quantidades de caranguejos saem em andada".

Logo, diz-se que a "andada" é o fenômeno em que grandes quantidades de machos e de fêmeas abandonam suas tocas, perdem a agressividade e vagam pelo manguezal para acasalarem-se e, no caso das fêmeas, realizar a desova (BLANKENSTEIN, et al., 1997). Foi observado pelos pescadores que na época da "andada" ocorre uma movimentação intensa de caranguejos nos manguezais, o que remonta, então, a nomenclatura.

Nordi (1992) observou entre os pescadores de Várzea Nova (PB) a associações desta fase de reprodução a uma "festa" (diversão) ou a uma doença ("doentes"), por conta dessa grande movimentação, também observada na região do Tamatateua. Outro fator observado pelos pescadores é que o fenômeno da "andada" acontece no início do ano, na lua nova e cheia, como firmado na fala de um pescador:

Na lua cheia e nova os caranguejos ficam tudo doido pelo mangal, ai a gente já sabe que começou a andada (Pescador B).

Nunes (1998, p. 17) também registrou a informação de pescadores nos manguezais de Vitória - ES, que a "andada acontece normalmente na primeira lua de janeiro (lua cheia ou nova)". Observa-se que no período de maio a agosto o caranguejo fica no período de engorda, que é identificado pelos extrativistas como os meses que não tem $R$. Todavia, não há até o presente momento comprovação científica ao fato de os meses não terem $R$, pode acontecer, talvez, por coincidência. Ou seja, é um ou outro conceito repassado através das gerações. 
Assim, em seguida, a bioecologia também diz que o caranguejo-uçá se prepara para a troca de casco, onde os pescadores afirmam que nesse período há uma diminuição no estoque de Ucides cordatus. Os caranguejos que estão nesse período da ecdise (muda) caracterizado como uma etapa de crescimento, ocorrendo geralmente uma vez por ano em indivíduos adultos, sendo mais frequente em jovens (ALVES \& NISHIDA, 2002).

Todavia, na fase da ecdise, os pescadores os consideram como impróprio para consumo, com ocorrência maior no mês de agosto. De acordo com os pescadores da região pesquisada, há uma diferença de meses de uma localidade para outra, como afirma Dalabona \& Silva (2005), espécies com grande distribuição geográfica podem apresentar períodos reprodutivos diferentes, de acordo com a latitude que ocorrem.

Segundo o IBAMA (1994), outra grande ameaça aos estoques de caranguejo-uçá envolve a captura durante o período da "andada", quando os machos e fêmeas saem de suas tocas para acasalarem-se e tornam-se presas fáceis. A despeito da proibição legal, este comportamento foi observado em várias comunidades de pescadores em que se predomina a produtividade de caranguejos (ANDRADE, 1983; NORDI, 1989; MANESCHY, 1993; NUNES, 1998; BARROS, 2001; ALVES, 2002; FISCARELLI \& PINHEIRO, 2002).

Interessante, ressaltar as observações realizadas por Nordi (1994), quando argumenta que as leis burocráticas que regulamentam a pesca do caranguejo-uçá são quase sempre inócuas, porque não consideram os saberes dos pescadores para a elaboração e aplicação efetiva da legislação ambiental, tão pouco contemplam a situação de vulnerabilidade econômica e social em que vivem esses pescadores.

Nesse sentido, os saberes ecológicos locais podem ser manifestados por meio da educação não formal, ou seja, acessados a partir do processo de percepção e deve considerar o saber tido como autêntico advindo de profissionais dessa atividade laboral. Podem ser “contados na igreja", nas "reuniões comunitárias", nos "locais de trabalho dos pescadores (manguezais)", como bem argumentam Brandão (2007) e Gohn (2010).

\subsection{AS TÉCNICAS DE PESCA DO CARANGUEJO-UÇÁ NO SABER DO PESCADOR DE TAMATATEUA}

A técnica de captura do caranguejo-uçá na região estudada é predominantemente o braceamento e o gancho. No primeiro, os pescadores introduzem o braço na galeria (toca) onde os caranguejos se localizam, imobilizando-os e os retirando e, em seguida, os imobilizam com uma quantidade de lama de mangue por meio de um enlace mobilizador das 
patas. No estuário do rio Mamanguape foi observado por Nascimento, Mourão e Alves (2011, p. 115) que "a coleta é feita de forma manual, com os catadores introduzindo o braço nas galerias, onde os animais se abrigam, para retirá-los depois de imobilizados".

Há outra técnica enumerada pelos pescadores da comunidade de Tamatateua que é utilizada quando as galerias estão muito profundas: a introdução da perna, onde se utilizam dessa técnica para acessarem o caranguejo com o pé, trazendo-o até certo ponto do alcance do recurso pelo braceamento. Logo, percebe-se o quanto os pescadores tendem a se adaptar aos obstáculos e mudanças encontrados na extração desse recurso.

Contudo, quando o caranguejo-uçá está profundo na lama do manguezal que nem o pé alcança, empreende-se a técnica do gancho. Este consiste em um vergalhão com ponta curvada fixado na ponta de uma haste de madeira com amarrilhos para fixar os dois (vergalhão e madeira) na constituição de um apetrecho eficaz na captura do espécime.

O apetrecho acima se utiliza da seguinte estratégia: os pescadores introduzem verticalmente o gancho na galeria até tocar no caranguejo, para depois removê-lo. Há a ressalva de que os pescadores utilizam essa técnica somente quando o "braceamento" e o "perneamento" não alcançam o recurso. Observa-se que essa técnica, às vezes, leva o caranguejo a óbito no ato da captura, devido à pressão na carapaça e, por conseguinte, sobrevive menos após ser capturado. Essa consequência também é percebida devido à redução no sucesso comercial, pois os animais têm que chegar vivos ao consumidor final.

\subsection{OS PESCADORES DE CARANGUEJO-UÇÁ E A OCORRÊNCIA DOS FENÔMENOS LUNARES}

Sabe-se que a lua tem influência direta sobre a vida na terra, principalmente no ambiente marinho, onde diversos animais tem seu ciclo reprodutivo e de vida ligado às marés e suas variações, segundo Alves e Nishida (2002). Nesse cenário, argumenta-se que as comunidades consideradas extrativistas de recursos do manguezal, tem um conhecimento robusto sobre as influências lunares no ciclo, pois isto se torna base para o processo de extração dos recursos desse ecossistema (ANDRADE, 1983).

Nordi (1994) afirma que os pescadores de caranguejo apresentam saberes importantes sobre os aspectos etológico, biológicos e ecológicos dos recursos pesqueiros com o qual interagem, assim como conseguem perceber a influência dos ciclos lunares e de maré sobre fauna e a flora, associando, principalmente, a atividade de catação de moluscos às fases da lua. 
De acordo com os pescadores de Tamatateua, o período de troca de casco está diretamente ligado às fases da lua, pois as marés ficam variando e o manguezal é inundado, o caranguejo procura lugares altos e enxutos, mas também se enterra dentro do manguezal. Como depoimento para essa assertiva, transcreve-se a fala: "nas quebras o caranguejo é mais raso" (PESCADOR C). Esse fato também foi verificado no estuário do rio Mamanguape, na Paraíba, por Alves e Nishida (2002, p. 114):

Os catadores ressaltam, ainda, que alguns caranguejos retardatários não conseguem fazer o "buraco" para se embatumar durante a maré de quebramento. Nesse caso, eles fazem uma "barroca" (buraco pequeno) ou procuram qualquer pequena depressão existente no substrato, onde permanecem até a ecdise.

As marés de quebramento são caracterizadas por Alves e Nishida (2002, p, 113) da seguinte maneira:

(...) por ocasião da passagem das luas nova e cheia para os quartos crescente e minguante, têm-se as "marés de quebramento", que diminuem gradativamente a cada dia, até produzirem as oscilações mínimas, próximo aos quartos de lua. Durante esse período, a porção inundável de mangue na preamar e descoberta na baixa-mar é menor.

Nesse sentido, observou-se que os pescadores de Tamatateua possuem saberes ecológicos locais elaborados com relação aos fenômenos naturais de maior ocorrência e interferência direta nas suas práticas produtivas, como é o caso da maré. Adicionalmente, referencia-se essa questão por meio das observações de Nordi (1994, p. 41), em que ressalta: "os catadores de caranguejo possuem um conhecimento elaborado acerca do comportamento da maré, em virtude da sua importância como fator regulador da atividade de 'catação"'.

\subsection{SIGNIFICADOS DO MANGUEZAL PARA OS PESCADORES DE CARANGUEJO-UÇÁ DE TAMATATEUA}

Os pescadores relataram as principais mudanças ocorridas nos manguezais atualmente, entre elas, destacaram-se: mais pessoas no manguezal (7\%), maior dificuldade de acesso (57\%) e agressão ao manguezal (36\%). O fator "dificuldade de acesso ao manguezal" se deve ao recurso mais longínquo, mais escasso. E, o fator "mais pessoas nos manguezais" foi justificado devido à ausência de emprego formal, ou seja, o elevado índice de pessoas desempregadas na região.

Ao analisar qual o significado do caranguejo-uçá para o dia a dia dos pescadores, verificou-se que para $28 \%$, é uma fonte de renda, e para $86 \%$ é meio de subsistência/alimentação. Noutra vertente, tem-se o significado. De acordo com Diegues e Arruda (1999), é importante analisar o sistema de representações, símbolos e mitos que esses 
povos possuem, pois a partir deles que agem sobre o meio natural. Ainda se detectou que o uso desse recurso se deve à complementação alimentar, assim como fonte de sobrevivência temporária (100\%). E, 64\% se deve a prática dinâmica da comercialização.

Simultaneamente, coloca-se a ideia de que o manejo dos recursos naturais, típico do modo de vida dos povos tradicionais, é permeado pela "necessidade do uso racional desses recursos" (ALMEIDA \& CUNHA, 1999, p. 1). E, esses recursos só se mantêm e continuam abundantes por esse uso racional existente, pois se observa a grande preocupação que os pescadores tradicionais tem, principalmente na época do defeso, como se constata na fala: " $O$ período do defeso é muito importante, porque é quando o caranguejo sai para cobrir a fêmea e procriar mais caranguejo" (Pescador F).

Situação bem interessante com relação aos saberes ecológicos locais se deu quando, $43 \%$ dos pescadores disseram que o período do defeso estipulado pelos órgãos ambientais está correto. Todavia, 57\% afirmaram que esse período está equivocado, como se observa na fala: “O defeso não está dando certo nas marés, porque falta um fiscal para saber quando o caranguejo se perde" (Pescador D).

Nesse sentido, questionou-se: “qual atitude se toma quando esse período determinado por lei não compreende os verdadeiros dias que deveriam ser o defeso?". Primeiramente, responderam obedecer a Lei. Entretanto, quando percebem a "andada" noutros dias não determinados em lei, alguns relataram não pescar, mas a maioria, 62\%, disseram pescar.

Mesmo que se possa observar que o trabalho no manguezal é feito, em sua maioria, para obtenção de complemento alimentar e de fonte de renda, os pescadores criam uma relação com o manguezal e o sentimento de pertencimento. Toledo (2000) ressalta que o pensamento entre população tradicional e meio ambiente é sempre para o bem. Noutra vertente, Diegues (2008), afirma que essa relação é uma visão do "bom selvagem”.

A idealização de que a relação das populações tradicionais com a natureza é harmoniosa e equitativa, está vinculada ao mito do "bom selvagem", mesmo que a relação da população com a natureza não siga essa visão romântica, não podemos levar para o extremo. Pois é perceptível que a relação das comunidades tradicionais com a natureza tem seus benefícios, pois estas desenvolvem formas de manejar benéficas ao ecossistema, pois entendem o recurso de muita importância para o seu dia a dia (MANESCHY, 2005; OLIVEIRA, 2015). Nessa mesma discussão, Almeida \& Cunha (1999, p. 1) afirmam que, 
explicitamente conservacionista e que, não obstante, seguem regras culturais para o uso dos seus recursos naturais de maneira sustentável.

Valores e regras de relação com a natureza são difundidos da própria cultura para a continuidade e propagação desse manejo sustentável com o recurso. Logo, ressalva-se que a noção de que homem e natureza não são independentes, visto que, o vínculo entre eles se constitui numa relação simbiótica, na qual "ambos desempenham funções para a manutenção do meio, sendo as ações humanas desenvolvidas neste contexto permeadas por diversos valores e regras, próprios da cultura pela qual são difundidos" (DIEGUES, 2008, p. 63). Há falta de valorização dos esforços dessa população para conservação da biodiversidade e a relação de subsistência existente, da qual depende diretamente.

Por fim, observa-se que os saberes dos povos tradicionais, em especial, dos pescadores de caranguejo-uçá de uma comunidade costeira da Amazônia brasileira, certamente, são alimentados, assegurados e contínuos em função do processo de ensino por meio dos mais velhos e de aprendizagem cotidiana pelos mais novos, a partir da compreensão da educação não formal e informal.

Diz-se isso, finalmente, porque o presente estudo conseguiu demonstrar que essas duas dimensões de educação, não formal e informal, estão presentes no fazer do dia a dia, sejam nas rodas de conversas, nos seus ambientes de trabalho ou mesmo nas suas reuniões comunitárias. A educação não formal foi observada quando o pescador revela que o seu aprendizado se deu por meio do fazer familiar e a educação informal, quando o pescador revela que aprende a prática da pesca na observação dos mais velhos, pais, amigos e outros.

\section{CONSIDERAÇÕES FINAIS}

Conclusivamente, diz-se que os pescadores do caranguejo-uçá da comunidade de Tamatateua, possuem um vasto conhecimento sobre os saberes ecológicos locais, em especial, sobre a prática produtiva desse recurso. E, por vezes, esse saber é compatível com a literatura científica disponível. As percepções sobre os caranguejos e os fenômenos ambientais relacionados, oferecem informações referentes ao manejo do recurso e a conservação dele. Nesse ínterim, apresentam estratégias sustentáveis de otimização da captura, uma vez que demonstram atitudes conservacionistas ladeadas pela aprendizagem cultural de forma, certas vezes, não intencional. Assim como também se utilizam de prática não conservacionista, como é o caso do uso do gancho. 
Por fim, fica evidente que a comunidade envolvida com a pesca do caranguejo-uçá pode fornecer informações importantes que venham a subsidiar pesquisas científicas e, ainda, contribuir para o estabelecimento de normas que regulamentem a referida atividade. Nesse sentido, abrem-se os questionamentos: por que os órgãos ambientais não acessam os povos tradicionais para "determinar" leis? Os saberes ecológicos locais não são válidos para referenciar a tomada de decisões? E por que a educação não formal e informal não é tida como referência para a prática docente ou mesmo nos cursos de graduação em licenciatura? Logo, os referidos questionamentos dizem que a presente pesquisa não se encerra, mas inicia uma discussão na modalidade educação não formal e informal, a partir dos saberes empíricos e ecológicos locais.

\section{REFERÊNCIAS}

ALMEIDA, Marissônia Lopes de; CUNHA, Manuel. Populações tradicionais e conservação. In: Programa Nacional da Diversidade Biológica. Seminário de Consulta. Avaliação e identificação de ações prioritárias para a conservação, utilização sustentável e repartição dos benefícios da biodiversidade da Amazônia brasileira. Macapá, 1999.

ALVES, Rômulo Romeu Nóbrega \& NISHIDA, Alberto Kioharu. A ecdise do caranguejouçá, Ucides cordatus (Crustácea, Decapoda, Brachyura) na visão dos caranguejeiros. Interciência. Vol. 27(3): 110-117, 2002.

ALVES, Rômulo Romeu Nóbrega. Estrutura populacional de Ucides cordatus (L., 1763) (Decapoda, Brachiura) e a atividade de coleta no manguezal do estuário do rio Mamanguape, Paraíba: um enfoque social e etnoecológico. 2002. 156 fls. Dissertação (Mestrado em Biologia) - Universidade Federal da Paraíba, Brasil, 2002.

ALVES, Rômulo Romeu Nóbrega; NISHIDA, Alberto Kioharu. Aspectos socioeconômicos e percepção ambiental dos catadores de caranguejo-uçá Ucides cordatus cordatus (L. 1763) (Decapoda, Brachyura) do estuário do rio Mamanguape, Nordeste do Brasil. Interciência, Caracas, v. 28, n. 1, p. 36-43, jan. 2003.

ANDRADE, Julieta de. Folclore na região do Salgado, Pará. Segredos na alimentação: profissões ribeirinhas. $2^{a}$ ed. Escola de Folclore, São Paulo, Brasil, 1983.

BAILÃO, Cheila Aparecida Gomes (Coord.). Gestão e educação ambiental: relatos de experiências sobre a questão ambiental. Vol. 2. Santo André: SEMASA, 2001.

BARBOSA, Andréa Geisa Pereira; MIRANDA, Indiana Katrine Arruda; CAVALCANTEFILHO, Wagner Gondim; SILVA, Débora Rodrigues Pinto. A importância do turismo na vida dos caranguejeiros no município de Parnaíba-PI. Fortaleza. Anais... Fortaleza: 2008. p. 1-8. 
BARROS, C. M. B. Conhecimento tradicional, conservação e sobrevivência: a importância da participação dos caranguejeiros na definição de políticas de proteção e manejo do manguezal de Mucuri-Bahia. 2001, 149 fls. Dissertação (Mestrado em Ciências Sociais) Universidade Federal de Alagoas, Brasil, 2001.

BAUER, Martin W. \& GASKELL, George. Pesquisa qualitativa com texto, imagem e som: um manual prático. Petrópolis, Rio de Janeiro: Vozes, 2002.

BLANKENSTEYN, Arno; CUNHA-FILHO, D.; FREIRE, A. S. Distribuição, estoques pesqueiros e conteúdo proteico do caranguejo de mangue (Ucides cordatus) (L. 1763) (Brachyura: Ocypodidae) nos manguezais da baía das laranjeiras e adjacência, Paraná, Brasil. Arquivos de Biologia e Tecnologia, 1997.

BORCEM, Elielma Ribeiro; FURTADO-JÚNIOR, Ivan; ALMEIDA, Inailde Corrêa; PALHETA, Marllen Karine Silva; PINTO, Ivanilde Albernás. A atividade pesqueira no município de Marapanim-Pará, Brasil. Revista Ciências Agrárias, Belém, v. 54, n. 3, p. 189201, set./dez. 2011.

BRANDÃO, Carlos Rodrigues. O que é Educação. São Paulo: Brasiliense, 2007.

BRASIL. Portaria $\mathbf{N}^{\mathbf{0}} \mathbf{0 3 4}$ /03-N, de 24 de Junho de 2003. Ministério do Meio Ambiente. Instituto Brasileiro do Meio Ambiente e dos Recursos Naturais Renováveis (IBAMA). Brasil: Brasília, 2003.

DALABONA, Gláucia; SILVA, Jaime de Loyola e. Período reprodutivo de Ucides cordatus (Linnaeus) (Brachyura, Ocypodidae) na Baía das Laranjeiras, Sul do Brasil. Acta Biol Par 34:115-126. 2005.

DIEGUES, Antônio Carlos. O mito moderno da natureza intocada. São Paulo: NUPAUB Núcleo de Apoio à Pesquisa sobre Populações Humanas e Áreas Úmidas Brasileiras USP/HUCITEC, 2008.

DIEGUES, Antonio Carlos; ARRUDA, Rinaldo Sérgio Vieira; SILVA, Viviane Capezzuto Ferreira da Silva; FIGOLS, Francisca Aida Barboza; ANDRADE, Daniela (Orgs.). Saberes tradicionais e biodiversidade no Brasil. Brasília: Ministério do Meio Ambiente, 2000.

FISCARELLI, Ana Gláucia; PINHEIRO, Marcelo Antonio Amaro. Perfil socioeconômico e conhecimento etnobiológico do catador de caranguejo-uçá, Ucides cordatus (Linnaeus, 1763), nos manguezais de Iguape ( $24^{\circ} 41^{\prime}$ S), SP, Brasil. Atualidades Biológicas, v. 24. n. 77, p. 39$52,2002$.

FOUCAULT, Michel. A Arqueologia do saber. Rio de Janeiro: Forense, 1986.

FREITAS, Henrique; MOSCAROLA, Jean. Análise de dados quantitativos \& qualitativos: casos aplicados usando o Sphinx ${ }^{\circledR}$. Porto Alegre/RS: Sphinx, 2000.

GOHN, Maria da Glória. Educação não formal e o educador social: atuação no desenvolvimento de projetos sociais. São Paulo: Cortez, 2010. 
IBAMA. Instituto Brasileiro de Meio Ambiente e Recursos Renováveis. Brasília, Brasil, 1994.

IBGE. Instituto Brasileiro de Geografia e Estatística/PNAD. Rendimento. Brasília, Brasil, 1999. Disponível em: www.ibge.gov.br. Acesso em: 05 jun. 2018.

MANESCHY, Maria Cristina. Pescadores nos manguezais: estratégias técnicas e relações sociais de produção na captura de caranguejo. In: FURTADO, Lourdes; LEITÃO, Wilma \& MELO, Alex Fiúza de. (eds). Povos das Águas: realidade e perspectivas na Amazônia. Museu Paraense Emílio Goeldi, Belém, Brasil, 1993, p. 19-62.

MANESCHY, Maria Cristina. Sócio-Economia: Trabalhadores e trabalhadoras nos manguezais. In: FERNANDES, M. E. B. (Org.). Os Manguezais da Costa Norte Brasileira. vol. II. Fundação Rio Bacanga, São Luís, 2005.

MINAYO, Célia S. (Org.). Pesquisa Social: teoria, método e criatividade. 29 ed. Petrópolis, R J: Vozes, 2010.

MONTEIRO, Marcos Alexandre Borges; OLIVEIRA, Francisco Pereira de; ARAÚJO, José Nazareno; FERNANDES, Marcus Emmaneul Barroncas. Productive Chain of the Mangrove Crab (Ucides cordatus) in the Town of Bragança, in the Northem Brazilian State of Pará (Amazon Region). Journal of Coastal Research, Special Issue. 70, 443-447. 2014.

NASCIMENTO, Douglas Macedo de; MOURÃO, José da Silva; ALVES, Rômulo Romeu Nóbrega. A substituição das técnicas tradicionais de captura do caranguejo-uçá (Ucides cordatus) pela técnica "redinha" no estuário do rio Mamanguape, Paraíba. Ciências Biológicas 11(2), Campina Grande, Paraíba, Brasil, p. 113-119. 2011.

NORDI, Nivaldo. A captura do caranguejo-uçá (Ucides cordatus) durante o período reprodutivo da espécie: o ponto de vista dos caranguejeiros. Rev. Nordestina Biol, 9. p. 4147. 1994.

NORDI, Nivaldo. Aspectos da interação dos pescadores-catadores com seu meio ambiente, com ênfase nos caranguejeiros. In: Anais do Encontro de Ciências Sociais e o Mar. São Paulo, Brasil, p.133-140. 1989.

NORDI, Nivaldo. Os catadores de caranguejo-uçá (Ucides cordatus) da região de Várzea Nova-PB: uma abordagem ecológica e social. 1992. 107 f. Tese (Doutorado em Ecologia e Recursos Naturais)-Universidade Federal de São Carlos, São Carlos, 1992.

NUNES, André Gustavo Alves. Os argonautas do mangue: uma etnografia visual dos caranguejeiros do município de Vitória-ES. 123 fls. Dissertação (Mestrado em Multiméios) Universidade Estadual de Campinas, Brasil, 1998.

OLIVEIRA, Francisco Pereira de. Análise da percepção dos extrativistas estuarinocosteiros sobre as de extração do caranguejo-uçá (Ucides cordatus) e madeireira do manguezal da costa amazônica brasileira. 160 fls. Tese (Doutorado em Ecologia de Ecossistemas Costeiros) - Programa de Pós-Graduação em Biologia Ambiental. Instituto de Estudos Costeiros/UFPA, 2015. 
RICHARDSON, Roberto Jarry. Pesquisa social: métodos e técnicas. São Paulo: Atlas, 1989.

TOLEDO, Victos M. Indigenous Knowledge on Soils: An Ethnoecological Conceptualization. In: BARRERA-BASSOLS, N.; ZINCK, J. A. Ethno ecology in a worldwide perspective: an annotated bibliography. Enschede: International Institute for Aerospace. Survey and Earth Sciences, p. 1-9, 2000.

VERGARA FILHO, W. L. \& PEREIRA FILHO, O. As mulheres do caranguejo. In: Ecologia e Desenvolvimento. Vol. 5(53): 34-36, 1995.

Recebido em: 28/10/2019

Aprovado em: 30/11/2019 